\title{
Política de defesa no Brasil: considerações do ponto de vista das políticas públicas
}

\author{
$\overline{\overline{2}}$ \\ Carlos Wellington de Almeida \\ Programa de Doutorado em Administração \\ Universidade de la Empresa - UDE \\ Montevidéo, Uruguai
}

\begin{abstract}
Resumo: Este artigo analisa a política de defesa do Brasil como uma política pública. Como metodologia, fez-se um benchmarking de conceitos e foram tratadas as informações obtidas de forma qualitativa, transpondo, da literatura das políticas públicas, os conhecimentos necessários à compreensão da defesa nacional como bem público provido pelo Estado. A ideia de integração de diferentes áreas do conhecimento domina a pesquisa e se vê refletida, também, nas conclusões relativas à necessidade de integração de diferentes setores da sociedade. Conclui-se que a busca e o entendimento da política de defesa como bem público requerem superar visões preconcebidas e analisar a defesa nacional com ferramentas das políticas públicas.
\end{abstract}

Palavras-chave: políticas públicas; defesa; forças armadas; eficiência; transparência

\begin{abstract}
This article analyzes defense policy in Brazil as a public policy. Methodologically, a benchmarking of concepts was made and the information obtained was treated in a qualitative manner. Information and data needed to understanding national defense as a public good to be provided by the state were prospected from public policy bibliography. The notion of integrating different knowledge areas is present in the whole research permanently as well in the conclusions related to the need of integrating diverse branchs of the society. The search for and the understanding of defense policy public as a public good demand to overcome biased concepts and to analyze defense with the use of public policy tools.
\end{abstract}

Key words: public policy; defense; armed forces; efficiency; transparency 


\section{Introdução}

A defesa nacional deve ser entendida como um bem público provido à sociedade por meio de políticas públicas. O conceito weberiano de Estado, da comunidade que reivindica para si, com êxito, o monopólio da violência legítima (WEBER, 2003), tem sofrido sucessivas alterações. Novas ideias surgem constantemente e o conceito de Estado se mostra em franca e permanente evolução, bem como as ideias que Ihes são associadas. A simples necessidade de violência legítima não mais a justifica, e os instrumentos de força devem prover à sociedade, de forma eficiente, eficaz e transparente, os bens e serviços esperados.

A literatura disponível acerca da análise de políticas públicas é, muitas vezes e com razão, criticada por seu caráter excessivamente positivista e tecnocrático. A realidade mostra que as políticas públicas costumam ser o resultado de intensa interação entre atores políticos e não a imposição de fórmulas e cálculos para cada problema (RUA, 1998; REZENDE, 2005; BID, 2006). O próprio "pai" do conceito de policy science (a ciência das políticas públicas) Harold Lasswell, propõe uma abordagem que transcende o positivismo tecnocrático e sustenta a orientação contextual da análise:

"Lasswell enfatizava a importância da orientação contextual dos analistas de políticas, tanto individual quanto coletivamente (...) considerava tal orientação contextual indispensável à condução do questionamento racional, e defendia o uso da análise configurativacontextual no desenvolvimento de uma profissão das políticas públicas" (TORGERSON, 1985, p. 242) ${ }^{1}$.

Nada obstante, Celina Souza (2003, p. 15) destaca "o crescimento da área de políticas públicas na pesquisa acadêmica que se realiza atualmente no Brasil". Este artigo analisa a política de defesa do Brasil como bem público a ser provido pelo Estado. Apresenta, ainda considerações acerca da inserção da Política de Defesa Nacional (BRASIL, 2005) e da Estratégia Nacional de Defesa (BRASIL, 2008) no contexto das políticas públicas.

\footnotetext{
${ }^{1}$ Lasswell emphasized the importance of the contextual orientation of policy analysts, both individually and collectively. (...) considered such contextual orientation indispensable to the conduct of rational inquiry, and he urged the use of contextual-configurative analysis in the development of a policy science profession (tradução livre do autor no texto).
} 


\section{Política pública de defesa como resposta a problemas específicos}

O entendimento da política de defesa passa pela definição de políticas públicas (public policies). Celina Souza (2006, p. 26) as define como "o campo do conhecimento que busca, ao mesmo tempo, "colocar o governo em ação" e/ou analisar essa ação". Outra definição é a de que políticas públicas são os produtos da política, isto é "decisões e ações relativas à alocação imperativa de valores" (RUA, 1998, p. 1). Ou, ainda, no que se refere à resposta concreta aos problemas:

"A dimensão material policy refere-se aos conteúdos concretos, isto é, à configuração dos programas políticos, aos problemas técnicos e ao conteúdo material das decisões políticas" (FREY, 2000, p. 85).

A política de defesa (defense policy) trata de com problemas específicos, insuscetíveis de transferência à iniciativa privada ou a qualquer outro campo da gestão governamental, e procura implementar soluções para esses problemas. Questões como a resposta a agressões externas não podem ser objeto da atuação das áreas da saúde ou da educação. Muitas vezes, as forças armadas, principal instrumento da defesa, estão engajadas em ações típicas das outras áreas governamentais, como é o caso do Correio Aéreo Nacional (CAN), realizado pelas aeronaves da Força Aérea Brasileira (FAB), ou da assistência às populações ribeirinhas da Amazônia, pelos navios-hospital da Marinha do Brasil. Isso decorre da natural ociosidade das forças em tempos de paz, mas é certo que o seu objeto específico, o uso das armas como instrumento da política, não se amolda à ação dos demais setores do governo.

Um esforço de enquadramento da defesa nacional nesse contexto foi feito com a publicação dos elementos Política de Defesa Nacional (BRASIL, 2005) e da Estratégia Nacional de Defesa (BRASIL, 2008), que constituem o eixo normativo básico da defesa nacional no Brasil. O primeiro é, em essência, a continuação da anterior Política de Defesa Nacional (BRASIL, 1996), publicada durante o governo Fernando Henrique Cardoso, e constitui o documento vinculante de maior hierarquia da defesa nacional. Já o segundo, a Estratégia, verdadeira inovação trazida durante o governo Luiz Inácio Lula da Silva, representa um desdobramento essencial da Política, voltado para a implementação de ações concretas no campo da defesa. 


\section{Aspectos político, jurídico e econômico da política de defesa}

Como as demais políticas públicas, a de defesa também pode ser entendida sob a forma dos conceitos político, jurídico e econômico. A política de defesa precisa ser entendida sob o prisma dos diferentes campos de conhecimento e das distintas realidades sociais, pois do contrário, pode ser transformada em um emaranhado de ações governamentais incompreensíveis para o cidadão e incapaz de obter o necessário suporte político-administrativo.

O conceito político de políticas públicas tem como engrenagem central a ideia de que determinados resultados desejados pela política somente têm chance de ocorrer quando contam com a força coercitiva do Estado. São chamadas "públicas" por terem origem e amparo no Poder Público e não são, de forma alguma, privadas, não se sujeitam às características do mercado. Como relembra Rua:

“As políticas públicas são 'públicas' - e não privadas ou apenas coletivas. A sua dimensão 'pública' é dada não pelo tamanho do agregado social sobre o qual incidem, mas pelo seu caráter 'imperativo'. Isto significa que uma das suas características centrais é o fato de que são decisões e ações revestidas da autoridade soberana do poder público (RUA, 1998, p. 2)."

A política de defesa, sob esse ponto de vista, constitui política pública porque sua realização somente é possível com a intervenção da força estatal, da qual, reciprocamente, constitui um dos principais instrumentos. A defesa é uma atividade típica do Estado, indelegável para o setor privado e, até, para outro setor do próprio Estado. É possível bem conceber unidades das forças armadas desempenhando ações típicas das áreas da saúde ou da educação, o que ocorre frequentemente; contudo, ver os servidores dos Ministérios da Saúde e da Educação com equipamentos de combate em uma operação de guerra já seria incomun.

Ainda do ponto de vista político, a defesa nacional deve constituir uma política de Estado e não uma política de governo. Deve haver um arranjo político subjacente à estrutura de defesa nacional, que, ao reunir militares e civis, partidos políticos e sociedade, permita sua condução acima das simples rivalidades. Possibilitando participação ativa na definição de prioridades, alocação de recursos e elaboração do orçamento.

Já o conceito jurídico nasce do aspecto político, mas dele se diferencia na essência da definição. Segundo essa ótica, uma política é pública define-se na 
estrutura constitucional-legal. É o caso da defesa, presente na estrutura constitucional do Brasil como responsabilidade do Estado. O que resta definir, do ponto de vista jurídico, é o alcance que devem ou podem ter as ações de defesa nacional, para que o uso da força estatal não viole direitos e garantias. 0 aparato militar, relembra-se, constitui instrumento da defesa e existe para servir à sociedade, não o contrário².

Finalmente, tem-se o conceito econômico de políticas públicas. Este deriva da noção de bem público prevista na moderna teoria econômica, que inclui as noções de não-rivalidade e não-exclusividade. Por bem não-rival entende-se aquele que consumido, utilizado ou demandado por alguém, não impede ou reduz a disponibilidade para outros. Bem não-exclusivo é aquele cujo proveito ou uso não pode ser individualmente impedido pelo provedor. Políticas públicas seriam aquelas destinadas a prover à sociedade bens e serviços não-rivais e não-exclusivos. A defesa nacional configura um bem (ou serviço) público, ou seja, o fato de um cidadão "usufruir" da defesa não significa que outro cidadão não possa fazer o mesmo (bem não-rival) e, também, o Estado não é capaz de impedir um ou outro cidadão de usufruir do mesmo bem (bem não-exclusivo) (SANDLER; HARTLEY, 1995; MANKIW, 2006).

A noção do consumidor oportunista (do inglês free-rider), adjacente ao conceito econômico do bem público, quer dizer que é possível que um cidadão que "não pague" pelo bem ou serviço provido via políticas públicas (sonegador de impostos, por exemplo) dele usufrua na mesma intensidade que aquele que "pague" normalmente por ela (contribuinte em situação regular) (MANKIW, 2006). E, novamente, tem-se como exemplo o "bem/serviço" defesa nacional: o cidadão que não paga seus impostos usufrui da paz, garantida pela política de defesa, na mesma medida em que aquele que paga seus impostos dela também goza. Do ponto de vista econômico, pode-se dizer, a defesa nacional constitui um bem público típico.

O corolário da análise econômica da política de defesa é que, dificilmente o setor privado terá interesse pelo fornecimento do bem ou serviço em questão, dadas as características de não-rivalidade e não-exclusividade, aliadas à presença do free-rider. O fornecimento do "bem" defesa não se amolda às noções de lucro e preço típicos da iniciativa privada embora isso não signifique que a iniciativa privada não possa participar das atividades periféricas ao provimento da defesa, como é o caso,

2 É oportuno ressaltar que outras políticas públicas, como a de segurança pública e a de inteligência passam pelo mesmo dilema e muito desse conflito é devido, exatamente, à umbilical ligação dos sistemas de segurança e inteligência à estrutura militar brasileira (CEPIK, 2001; MARQUES, 2001; ZAVERUCHA, 2006). 
por exemplo, das indústrias de material bélico. Entretanto, caberá ao Estado, diante da natureza inprescindível da defesa e da sua baixa aderência ao modelo de mercado, encarregar-se de sua entrega à coletividade.

\section{Traços essenciais da política pública de defesa}

O conceito de política pública adotado depende do contexto da análise, do padrão de conduta do operador de políticas ou, ainda, do objetivo pretendido. Não é possível, nem mesmo desejável, estabelecer-se uma dicotomia entre modelos corretos ou incorretos, bons ou ruins. Contudo, das diferentes definições e modelos disponíveis sobre políticas públicas, podem-se extrair e sintetizar elementos principais, identificados por Souza (2006), a seguir relacionados à política de defesa.

"A política pública permite distinguir entre o que o governo pretende fazer e 0 que, de fato, faz" (SOUZA, 2006, p. 36). Como nos demais setores da vida política, na defesa há algum distanciamento entre discurso e prática. No Brasil, um aspecto que tem sido colocado em relevo é o da submissão do aparelho militar ao controle civil. O discurso oficial, estampado tanto na Política de Defesa Nacional (BRASIL, 2005) quanto na Estratégia Nacional de Defesa (BRASIL, 2008), é enfático ao afirmar essa submissão, mas há analistas, e mesmo integrantes do governo, que sustentam a persistência de uma autonomia excessiva das forças armadas em relação à Presidência da República, ao Ministério da Defesa, ao Congresso Nacional e aos órgãos de fiscalização e controle (ZAVERUCHA, 2006).

"A política pública envolve vários atores e níveis de decisão, embora seja materializada através dos governos, e não necessariamente se restringe a participantes formais, já que os informais são também importantes" (SOUZA, 2006, p. 36).

Na política de defesa existem instâncias que não integram a estrutura formal do governo, mas que são fundamentais ao provimento do bem público esperado, como a indústria de material bélico. Outras áreas com competências específicas, como o meio acadêmico e o setor de ciência e tecnologia, também devem participar do processo de formulação e decisão das políticas públicas em defesa (BRANDÃO, 2005; PROENÇA JUNIOR e DUARTE, 2007). Essa participação de diversos setores é essencial à construção da legitimidade da política e maior será essa legitimidade quanto mais aberto for o leque de instâncias participantes. A 
Estratégia de Defesa Nacional, expressamente, reconhece como vulnerabilidade da defesa do Brasil a:

"Inexistência de planejamento nacional para desenvolvimento de produtos de elevado conteúdo tecnológico, com participação coordenada dos centros de pesquisa das universidades, das Forças Armadas e da indústria" (BRASIL, 2008).

"A política pública é abrangente e não se limita a leis e regras" (SOUZA, 2006, p. 36). Como nas demais políticas públicas, na de defesa as leis e regras são essenciais à definição do escopo de atuação, mas não constituem os seus únicos limites. Muito do que se passa na política de defesa é fruto de percepções, em permanente mutação, dos políticos civis, dos militares, da sociedade civil. No Brasil, atualmente, grande atenção é dada à Amazônia, percebida como alvo de cobiça internacional, o que levou ao deslocamento de antigas hipóteses de conflito da região sul para o norte do Brasil (SILVA, 2004). Mais recentemente, com a descoberta de petróleo na região oceânica do pré-sal, ganham força os aspectos marítimo e naval. Outras percepções, como as relativas à segurança pública e às ligadas ao tema do terrorismo também podem influenciar as decisões da política de defesa muito além das leis e regras que se propõem a regê-la. No Brasil, a Política de Defesa Nacional (BRASIL, 2005) e a Estratégia Nacional de Defesa (BRASIL, 2008) procuram conferir o tratamento mais amplo possível aos distintos temas relacionados à defesa.

"A política pública é uma ação intencional, com objetivos a serem alcançados" (SOUZA, 2006, p. 36). O objetivo central da política de defesa, idealmente, é o de garantir resposta, pela via militar, a agressões externas. O caráter intencional da ação é evidente e sinaliza a vinculação da política de defesa a um conjunto de ações que, por serem propositais, envolvem a responsabilidade dos tomadores de decisão e dos agentes executores. Ocasionalmente, em períodos prolongados de paz, não fica muito clara a necessidade da manutenção desse objetivo e o aparato de defesa é utilizado para tarefas que não dizem respeito à sua natureza. A Política de Defesa Nacional, expressamente, preocupa-se com o resgate do conceito de defesa nacional, ao enunciar, em seu item 1.4, que:

"Defesa Nacional é o conjunto de medidas e ações do Estado, com ênfase na expressão militar, para a defesa do território, da soberania e dos interesses nacionais contra ameaças preponderantemente externas, potenciais ou manifestas" (BRASIL, 2005). 
"A política pública, embora tenha impactos no curto prazo, é uma política de longo prazo" (SOUZA, 2006, p. 36). Esta é uma das principais razões para que a política de defesa seja considerada política de Estado e não de governo. A paz é um objetivo permanente das nações e sua garantia deve pairar acima de qualquer mudança de governo. Paradoxalmente, e nisso reside muito da dificuldade de se compreender o papel da defesa nacional, essa paz deve ser garantida, se necessário, com recurso à guerra ${ }^{3}$. A Exposição de Motivos que fundamentou a Estratégia Nacional de Defesa consagra a defesa nacional como objeto de uma política que deve ser pensada no longo prazo, ao reconhecer que:

"A atual iniciativa (...), de colocar as questões de defesa na agenda nacional e de formular um planejamento de longo prazo para a defesa do País é fato inédito no Estado brasileiro" (BRASIL, 2008)

"A política pública envolve processos subseqüentes após sua decisão e proposição, ou seja, implica também implementação, execução e avaliação" (SOUZA, 2006, p. 37). Uma das graves críticas que se faz às políticas públicas é que as decisões tomadas, muitas vezes, são perdidas nas etapas seguintes, e não recebem adequada avaliação. A política de defesa, no Brasil, não tem sido exceção a essa regra e parte das dificuldades encontradas na sua implementação reside na dificuldade de se chegar a um consenso sobre o desenho geral que deve ter o sistema de defesa. A Estratégia de Defesa Nacional, nesse sentido, constitui-se na primeira tentativa oficial concreta, no Brasil, de tentar superar o planejamento, a execução e a revisão "acidentais" da política de defesa e substituir esse histórico casuísmo por um modelo plurianual a contemplar diversos períodos de governo projetados para o futuro.

Por fim, em relação ao conceito de política pública, deve ficar clara a noção de trade-off que subjaz a todo o seu processo de formulação, ou seja, a decisão pela realização de determinada política pública implica, necessariamente, o sacrifício de outras opções, como decorrência da clássica oposição econômica entre necessidades infinitas e recursos limitados. Exemplo clássico é o da oposição entre

\footnotetext{
3 Diferenças entre diplomatas e militares brasileiros levaram as discussões quanto à adesão ao Tratado de Não-Proliferação Nuclear (TNP), decisão que levaria o Brasil para sempre, a afastar de sua política de defesa a possibilidade de uso de armas atômicas: típico efeito de longo prazo. A posição do Itamaraty venceu e o Brasil abdicou deste instrumento de força, incondicionalmente, aderindo ao TNP. Para a diplomacia, coerência com o perfil de soft power que se pretendia imprimir à inserção internacional do Brasil. Para os militares, obra arquitetada pelas potências do hemisfério norte, com o beneplácito dos diplomatas (CASTELAN, 2007).
} 
os investimentos em defesa e os investimentos na área social, permanente fonte de tensão entre o setor defesa e os demais setores da gestão pública.

\section{Demandas por políticas públicas de defesa no Brasil}

Demandas por políticas públicas são reivindicações da sociedade dirigidas ao poder público. Podem ser "reivindicações de bens e serviços, como saúde, educação, estradas" ou "demandas de participação no sistema político, como reconhecimento do direito de voto dos analfabetos" (RUA, 1998, p. 2). A decisão de se constituir uma política pública depende das demandas a ela relacionadas. No que se refere à política de defesa, no Brasil, a situação mostra-se particularmente complicada, dada a rarefeita necessidade do "bem" defesa. Isso se deve à ausência de ameaças visíveis ao estado atual de paz na América do Sul, à estabilidade das relações diplomáticas com países vizinhos e, também, à falta de comunicação adequada do sistema de defesa nacional. Mesmo países com situação política mais delicada, como a Colômbia e a Venezuela, não chegam a representar uma ameaça militar concreta ao Brasil.

Como resultado, o Ministério da Defesa e as forças armadas não têm conseguido transmitir à sociedade, de maneira clara, o verdadeiro conteúdo de sua missão, que permanece desconhecido. É oportuno enfatizar que não se devem confundir as demandas por defesa nacional com aquelas por maior participação das forças armadas no combate ao crime. Tratam-se, neste caso, de demandas relativas à segurança pública, conceito substancialmente distinto.

Novamente, tem-se que, para entender a questão da demanda por defesa faz-se necessário relacioná-la aos conceitos de políticas públicas. De foma a incluí-a a defesa em um padrão de análise possível de comparação com outras políticas públicas. Nesse sentido percebe-se que a política de defesa em pouco ou nada difere das demais no que se refere a essa estrutura analítica.

As demandas por políticas públicas podem apresentar-se sob a forma de inputs. Estes são "originários do meio ambiente" (RUA, 1998, p. 2), podendo chegar à arena política por diferentes meios, notadamente, por meio das organizações da sociedade civil, e por meio da classe política, sobretudo por meio dos parlamentares componentes da democracia representativa, que nesse momento atua no sentido de fazer com que o governo atenda à reivindicação da sociedade civil representada.

Outra forma de apresentação das demandas é a de withinputs: "distinguem-se dos inputs pelo fato de que são provenientes do próprio sistema político" (RUA, 1998, p. 3). No Brasil, as poucas demandas por políticas de defesa 
costumam ocorrer na forma de withinputs e são originadas nas próprias forças armadas, tendo o Ministério da Defesa uma participação ainda pequena quanto à geração das demandas. São raras e de pouco significado as interferências do Congresso Nacional e seus parlamentares, da sociedade civil organizada e mesmo das outras instâncias do Poder Executivo.

As duas versões da Política de Defesa Nacional (BRASIL, 1996; BRASIL, 2005), exemplificam esse hermetismo do tema, pois são decretos presidenciais e não leis produzidas com amplo debate legislativo. Como evolução positiva, pode-se dizer que a Estratégia Nacional de Defesa (BRASIL, 2008) traz em sua proposta a ideia de um debate mais amplo, contudo, trata-se, ainda, de uma construção incipiente. Oliveira (2006) se refere a quatro fatores explicativos, a seguir apresentados e comentados, para todo esse desinteresse pela política de defesa.

"Ao superar o passado autoritário, uma parte articulada da sociedade rejeitou as forças armadas" (OLIVEIRA, 2006). O que o professor Eliézer nos mostra é que as forças armadas passaram a ser vistas com desconfiança por boa parte dos principais formadores de opinião nos meios político, acadêmico e científico. Não sem motivo, as mais recentes ações da área de comunicação social do Ministério da Defesa e das forças armadas têm dado atenção a esse aspecto. A própria Estratégia Nacional de Defesa (BRASIL, 2008) é uma tentativa de romper com esse estado de coisas, mas ainda há um longo caminho a percorrer."

"Nossos governantes e legisladores parecem acreditar que não temos problemas de defesa" (OLIVEIRA, 2006). Esta crença decorre dos prolongados períodos de paz que vivemos e de uma sistemática incapacidade das lideranças do setor defesa para fazerem valer suas prioridades. Mesmo a participação brasileira nas operações de paz das Nações Unidas não tem sido percebida como algo que leve a política de defesa a ser incluída entre os temas mais relevantes da agenda nacional. Com certeza, não a elevou sequer perto dos patamares de importância de outras políticas públicas, tais como as de educação e de saúde.

"Vigora uma forte competição temática pelo interesse dos partidos e da sociedade civil" (OLIVEIRA, 2006). As carências sociais são tão alarmantes que não sobra espaço para a inclusão de temas de defesa nacional na agenda política prioritária do Brasil. São enormes as dificuldades encontradas pelo sistema de defesa nacional para justificar a continuidade de seus programas, diante das necessidades relacionadas à fome, à saúde e à educação. Nesse contexto, a política de defesa acaba "caindo" no ranking das prioridades nacionais e é tratada como assunto de menor importância. 
"Os temas prioritários 'dão votos', a defesa nacional 'não dá votos'” (OLIVEIRA, 2006). Os políticos preferem tratar outros assuntos, os quais se afiguram mais urgentes para a sociedade e apresentam resultados eleitorais mais imediatos para os representantes. A escolha, prossegue o professor Oliveira (2006), "é previsível: excluem a defesa nacional de qualquer consideração programática. 0 resultado é o insucesso na disputa pelos recursos destinados à defesa nacional".

Há ainda a noção de inputs, complementar à de inputs e withinputs, é a de outputs: os resultados efetivos, em termos de políticas públicas. São as respostas às reivindicações da sociedade e da classe política, oferecidas pelo poder público. Os outputs são, portanto, as políticas públicas propriamente ditas. No que se refere à política de defesa, como resultado de todas as dificuldades acima identificadas, os outputs costumam ser de baixa qualidade e pouco significado. Há, por exemplo, um visível descolamento entre o estabelecido na política de defesa do Brasil e o orçamento destinado à sua realização. Além disso, os custos parecem sempre altos e as forças armadas passam a impressão de serem grandes demais, uma despesa desnecessária, situação esta verificada tanto no Brasil quanto em muitos dos países vizinhos. A esse respeito, afirma Aguilar:

"Percebe-se que há uma enorme distância entre as ideias
estabelecidas nas políticas de defesa e os orçamentos destinados às
forças armadas em todos os países do Cone Sul. (...) Pode-se
afirmar que as Forças Armadas do Cone Sul não evoluíram o
necessário para assegurar a dissuasão prevista em todas as políticas
de defesa, além dos orçamentos comprometerem a preparação para
assegurar os interesses vitais das nações, conforme expressos nas
políticas." (AGUILAR, 2008, p. 119)

Demandas por defesa nacional, assim como por outros bens e serviços públicos, podem ser classificadas segundo a oportunidade de inserção no debate das políticas públicas. Existem demandas que "surgem" no debate e outras que "sempre estão lá". Há, ainda, aquelas que "deveriam estar" na arena dos debates políticos, mas não estão. De acordo com a pesquisadora Rua (1998), podemos classificar as demandas por políticas públicas em três tipos:

Demandas novas: "resultam do surgimento de novos atores políticos ou de novos problemas" (RUA, 1998, p. 3). São aquelas que "surgem" como novidade no debate político. Na defesa brasileira tivemos demandas novas quando, ao fim da Segunda Guerra Mundial, com a afirmação da propulsão a jato nos céus de todo o 
mundo, foram adquiridos os caças a jato F.8 Gloster Meteor. Ou, ainda, quando a experiência da guerrilha do Araguaia levou à criação do COSAC (Comando de Operações de Selva e Ações de Comando), posteriormente absorvido pelo CIGS (Centro de Instrução de Guerra na Selva). Em termos da política de defesa atual, demandas novas dizem respeito à necessidade de defesa naval a partir da descoberta de petróleo pela Petrobrás na região do pré-sal e, ainda, à preparação das forças armadas para agir contra o narcotráfico nas fronteiras.

Demandas recorrentes: "expressam problemas não resolvidos ou mal resolvidos, e que estão sempre voltando a aparecer no debate político e na agenda governamental" (RUA, 1998; p. 3). Demandas recorrentes, na política de defesa, são relativas ao projeto do submarino nuclear para a Marinha do Brasil, há décadas em execução, sucessivas vezes apresentado ao Congresso Nacional e às comissões parlamentares, sem resultados decisivos. Outro exemplo de demanda recorrente na defesa nacional brasileira é o da elevação da participação da defesa no orçamento nacional, sistematicamente considerado insuficiente pelos militares e, ao mesmo tempo, muito elevado por boa parte da classe política.

Demandas reprimidas: aquelas que não chegam até o sistema político, são barradas ou têm seu processo decisório trancado. No Brasil, em relação à política de defesa, costumam constituir-se a partir de assuntos considerados sensíveis demais para a cultura vigente. As demandas reprimidas podem constituir estados de coisa ou situações de não-decisão (RUA, 1998).

Estados de coisa: situações existentes há tempos sem, contudo, chegar a incomodar, por isso não entram na agenda governamental. São situações que não chegam "a pressionar o sistema e se apresentar como problemas políticos a exigirem solução" (RUA, 1998, p. 3). Na política de defesa nacional, um exemplo de estado de coisa diz respeito à questão dos homossexuais nas forças armadas, recorrentemente trazida às luzes pela imprensa nacional, mas sem chegar a ser incluída na agenda.

Não-decisão: assunto que chega à agenda política, mas tem a decisão obstruída. Em geral, a não-decisão se refere a "temáticas que ameaçam fortes interesses, ou que contrariam os código de valores" (RUA, 1998, p. 6). Era o caso da extinção do serviço militar, assunto tratado como verdadeiro tabu, principalmente pelo Exército Brasileiro. A atual Estratégia de Defesa Nacional (BRASIL, 2008) tenta chegar a um ponto final sobre o tema, ao fazer uma franca opção pelo serviço militar obrigatório. 
Prosseguindo em sua análise, Maria das Graças Rua define que uma demanda reprimida somente ingressa na agenda política quando "mobilize ação política", "constitua uma situação de crise" ou "constitua uma situação de oportunidade" (RUA, 1998, p. 6). É o que Kingdon (2003) chama de janelas de oportunidade (opportunity windows). Não é diferente o que ocorre com a política de defesa no Brasil. Sem apelo temático suficiente para mobilizar a opinião pública e sem a percepção de uma situação de crise que justifique o emprego da força armada, resta aos dirigentes da defesa nacional atuar segundo as situações ou janelas de oportunidade que se apresentem. Recentemente, das discussões surgidas em torno da descoberta de petróleo na região oceânica do pré-sal, surgiu importante opportunity window para o reforço da Marinha do Brasil.

\section{Atores públicos e privados na política de defesa}

Quando se analisam os personagens envolvidos no processo de formulação de políticas públicas, fala-se em atores políticos: personagens, individuais ou coletivos, envolvidos em conflitos acerca da alocação por bens e serviços públicos. Ao contrário do que o termo poderia induzir, atores políticos não são apenas os políticos profissionais. O cidadão comum, as associações de cidadãos e outras entidades são atores políticos a partir do momento em que se inserem na disputa por bens e serviços públicos. Os atores políticos podem ser divididos em públicos ou privados.

Atores públicos: "aqueles que se distinguem por exercer funções públicas e por mobilizar os recursos associados a estas funções. Dentre os atores públicos, por sua vez, pode-se diferenciar, grosso modo, duas categorias: os políticos e os burocratas" (RUA, 1998, p. 4). Essa subdivisão, de cunho weberiano (WEBER, 2003), ocorre o envolvimento do segundo o ator público no contexto da política eleitoral e de disputa pelos cargos de mando político ou faça sua participação no quadro permanente da administração pública, envolvido mais com a implementação das decisões do que com a tomada de decisões, propriamente dita. Na política de defesa brasileira, são atores públicos o Presidente da República, o Congresso Nacional, as comissões parlamentares, os políticos profissionais, os partidos políticos, o Ministério da Defesa, as forças armadas, os órgãos governamentais da área orçamentária, os servidores públicos desses órgãos, entre outros.

Atores privados: atores políticos que não mantêm vínculo profissional com o Estado, para fazer valer o seu interesse. É o caso das associações cidadãs, das 
organizações não-governamentais (ONGs), dos grupos de interesse, dos grupos de pressão e do cidadão comum. Não são menos importantes que os atores públicos, embora estejam mais distantes das ferramentas de implementação das políticas públicas. No mundo da defesa nacional, atores privados de importância capital são as indústrias de armamentos, quase sempre muito organizadas em torno de seus interesses.

A profícua proliferação de atores políticos, tanto públicos quanto privados, revela-se uma realidade contemporânea em todos os setores das políticas públicas, inclusive, no setor defesa nacional. Existe grande espaço para o fortalecimento da inserção de novos atores, públicos e privados, no processo de formulação das políticas de defesa. A própria noção contemporânea de democracia sustenta a atribuição de papéis cada vez mais relevantes a atores outrora considerados de pouca importância. Não são poucos os estudos que sustentam que o próprio povo deve, por ele mesmo, ser mais ativo nas decisões relativas às políticas públicas, inclusive as de defesa, e ajudar a geri-las e fiscalizá-las, em especial diante da permanente multiplicação dos atores sociais, dos avanços tecnológicos e do crescente acesso à informação (GARCIA, 2000; CANO, 2006; LEGALES e LASCOUMES, 2007).

No Brasil, a falta de debate sobre a defesa nacional não é fruto apenas do olhar enviesado que os militares lançam sobre as lideranças civis que se acercam do assunto, vendo-as, em geral, com suspeição e rotulando-as como incompetentes para o trato das questões. Também decorre essa situação do marcante desinteresse dessas lideranças por um assunto que deveria constituir importantíssima política de Estado. É verdade que os excessos do regime militar levaram à quase completa destruição do diálogo entre as forças armadas e os demais setores da vida social brasileira, contudo, não há razão para que não se supere essa indesejável situação. Autoridades civis, muitas vezes, sentem-se intimidadas porque ignoram as instituições da defesa. Nutrem, com relação aos militares, preconceitos construídos quando visões ideológicas irreconciliáveis dominavam a cena. Só muito recentemente, ampliou-se o grupo de políticos, acadêmicos, pesquisadores e jornalistas dispostos a conhecer as forças armadas e a dialogar com suas lideranças. Entretanto, se é verdade que as forças armadas não são mais independentes no que se refere à política de defesa, também é certo que ainda mantêm um elevadíssimo grau de autonomia, incompatível com a noção do controle civil e que somente será reduzido à medida que novos atores civis, públicos ou privados, se envolvam com o tema (MARQUES, 2003b; SANTANA, 2007; ROCHA, 2008). 
Um ator público que precisa mostrar-se mais ativo e exercer um papel de maior relevo é o Congresso Nacional, por meio do Senado Federal, da Câmara dos Deputados e das comissões parlamentares. Tradicionalmente afastado do tema da defesa e de outros assuntos espinhosos correlatos, como o sistema inteligência (MARQUES, 2003a), o parlamento brasileiro, generosamente, entrega o papel preponderante ao poder executivo, quando deveria com ele dividir o palco. 0 parlamento precisa chamar para si etapas importantes do processo de formulação da política de defesa, em especial, a decisão sobre o orçamento de defesa, o qual continua a ser uma "caixa-preta", com seus padrões definidos exclusivamente no âmbito do Poder Executivo, limitando-se o Congresso a efetuar "cortes", muitas vezes sem maior domínio sobre o assunto. Se o Legislativo deseja exercer efetivo controle sobre a defesa nacional deve ocupar-se da elaboração e da supervisão de seu orçamento, o qual constitui a peça material central do processo de concretização da política de defesa, em qualquer país (GIRALDO, 2001; BRIGAGÃO, 2007).

Outro ator político que tem muito a evoluir é o Ministério da Defesa. Criado em 1999 sob intensa pressão internacional e com ativa interferência do Itamaraty, sem que a diplomacia brasileira atribuísse às forças armadas qualquer prioridade como instrumento da política externa (LOPES, 2001; ALSINA JUNIOR, 2002; CASTELAN, 2007), o Ministério prossegue, até hoje, em seu calvário. A escolha de civis para a titularidade da pasta parece haver sido acertada ao sinalizar a intenção de efetivar o controle civil sobre as armas nacionais e, hoje, já se verifica uma redução do protagonismo militar na cena política brasileira (FERNANDES, 2006; FUCCILLE, 2006). No entanto, a simples escolha de um ministro civil mostra-se absolutamente insuficiente para a obtenção dos propósitos pretendidos. A situação institucional indefinida, a falta de interesse pelo tema da defesa e a hesitação em tornar os comandantes militares efetivamente subordinados ao ministro, fazem com que o ministro da defesa atue, na prática, como um simples "despachante institucional dos militares junto à Presidência da República" (ZAVERUCHA, 2006, p. 174) e não como o representante do poder político junto à estrutura militar da defesa nacional.

A comunidade acadêmica também precisa aproximar-se do tema da defesa nacional, pois a distância gera efeitos nocivos para as duas partes. A defesa sai prejudicada porque perde a oportunidade de contar com pesquisadores capazes de gerar conhecimento e, com isso, contribuir para o fortalecimento das instituições da defesa. Em se tratando de instituições que lidam com os temas da estratégia, do poder e do emprego da força, desperdiçar uma fonte de conhecimento significa desperdiçar uma fonte de força, o que é, no mínimo, incompreensível. O meio 
acadêmico também perde com esse distanciamento, pois não é admissível que um setor dedicado, à geração de conhecimento, abdique de atuar em um campo de estudos tão rico ${ }^{4}$.

Um reencontro entre as forças armadas e a academia traria resultados positivos para ambos os lados. A Estratégia de Defesa Nacional (BRASIL, 2008), atenta ao tema prevê, expressamente, a participação das universidades na formação de quadros civis para a defesa, na condução de estudos específicos sobre o setor defesa e no desenvolvimento de produtos de alta tecnologia de interesse militar. Nada obstante, o desafio de implementar essas ideias continua presente.

Enfim, no que se refere à sociedade como um todo, o tema da defesa parece ser encarado como distante e desinteressante. Erro maior não poderia haver: as grandes democracias também necessitam de estruturas de defesa para resguardar seus valores. É conhecida a fala de Georges Clemenceau, ministro francês que, ao fim da Grande Guerra (1914-1918), afirmou ser a guerra um assunto sério demais para ficar nas mãos dos militares. O que parece, muitas vezes, não haver sido bem compreendido, é que Clemenceau não criticava apenas os estamentos fardados pelos horrores da luta assassina que fez perecer uma geração inteira de jovens em campos lamacentos da Europa. Criticava, também, o distanciamento e a apatia das lideranças civis, que preferiam não assumir responsabilidades que Ihes eram de direito e por dever.

\section{Performance e transparência na gestão dos recursos da defesa}

A eficiência e a transparência são conceitos elevados aos patamares de primeira importância nos atuais estudos sobre políticas públicas. Diante da escassez de recursos para atender a infinitas demandas, a ideia do "fazer mais com menos" adquire importância capital. Conceito amplo que reúne as noções de eficácia e eficiência, e que se vincula nitidamente ao conceito de transparência, a performance da gestão pública, passa a ocupar posição central no debate sobre avaliação de políticas públicas e os estudos sobre o assunto adquirem crescente relevância. A política pública de defesa não é exceção: estruturas de gestão tradicionalmente alheias aos processos de reforço da transparência, têm nessa opacidade um importante obstáculo no caminho de uma melhor performance. Esta, por sua vez, pode ser entendida como a capacidade da gestão pública para, cumulativamente, atingir os resultados abaixo apresentados, assunto de seminário

${ }^{4}$ Eliézer Rizzo de Oliveira (2006) destaca que "no Brasil, com a exceção de alguns centros universitários de pesquisa e de umas poucas entidades de militares da reserva, predomina o silêncio". 
conduzido por Flávio da Cunha Rezende, relacionados com a política de defesa no Brasil:

"Estabelecer e manter prioridades de políticas" (REZENDE, 2005). No Brasil, a política pública de defesa não tem sido um dos melhores exemplos de coerência na manutenção de prioridades. Auditoria realizada pelo Tribunal de Contas da União (TCU) verificou que nas comissões de compras do Exército, Marinha e Aeronáutica em Washington e Londres trabalhavam não menos que 179 pessoas. Essas comissões constituem um "sonho dourado" para militares brasileiros, em razão do reforço que representam às suas remunerações. Contudo, pouco há que demonstre a necessidade de um contingente tão poderoso, com uma enorme proporção de oficiais de patente superior, na condição de "compradores". Na mesma época, o contingente militar que o Brasil enviou ao Timor Leste foi de 50 soldados apenas, sob alegação de dificuldades financeiras (ZAVERUCHA, 2006, p. 174)."O ciclo de reaparelhamento das forças também se apresenta de forma caótica, deixando o equipamento de combate, muitas vezes, oboleto. A Estratégia Nacional de Defesa (BRASIL, 2008) prevê a redução dos ciclos de reaparelhamento das forças armadas, mas praticamente nada diz a respeito de como serão no futuro.

"Focalizar e direcionar alocação de recursos" (REZENDE, 2005). Também, em relação a essa característica de performance em política pública, a defesa brasileira mostrase fraca. A começar pelo documento essencial, a política de defesa, que desde sua primeira versão, de 1996, não especifica funções claras nem permite entender a alocação de recursos (SANTANA, 2007; ROCHA, 2008). O gasto com pago de pessoal é elevado, consumindo cerca de $75 \%$ do total de recursos e deixando à míngua o reaparelhamento e o adestramento, e, do que resta, mais da metade (17\%) está comprometido com despesas obrigatórias (LOPES, 2001; FERNANDES, 2006; AGUILAR, 2008). O aumento da transparência na alocação de recursos revela graves incômodos por expor as mazelas das organizações, mas tem o condão de mobilizar opiniões e esforços para enfrentar problemas. Uma atuação mais intensa dos órgãos de controle, especialmente do Congresso Nacional e do TCU, é de capital importância: constantes alterações nas prioridades orçamentário-financeiras terminarão por significar o enfraquecimento do Legislativo como instância de controle e do próprio orçamento como ferramenta de planejamento estratégico e governança econômica (GIRALDO, 2001; SANTISO, 2003). A esse respeito, a Estratégia Nacional de Defesa (BRASIL, 2008), infelizmente, nada de concreto apresenta. 
"Produzir inovações em políticas públicas" (REZENDE, 2005). A política de defesa brasileira tem demonstrado pouca capacidade de inovação. Na verdade, continua sendo conduzida como há décadas atrás: pouca ou nenhuma coordenação entre as forças singulares, crônica fraqueza institucional do Ministério da Defesa, desempenho de papel secundário pelo Congresso Nacional, pouca articulação com a política externa, baixo grau de transparência no orçamento militar e pouca participação do meio acadêmico e da sociedade civil organizada nas principais decisões. É preciso mudar, radicalmente, a maneira de pensar a política de defesa, tornando-a, verdadeiramente, um assunto de interesse e conhecimento público. A esse respeito, a Estratégia Nacional de Defesa (BRASIL, 2008) constitui-se em importante expectativa de inovação, carente, ainda, de resultados práticos.

"Impor perdas a grupos poderosos" (REZENDE, 2005). Toda política pública constitui o resultado de uma escolha. A política de defesa sinaliza o que se faz e o que não se faz, quais necessidades são consideradas prioritárias e quais são secundárias, enfim, quem ganha e quem perde. Essa característica essencial de "escolha" dá o tom verdadeiramente político do tema e tem uma tendência natural a gerar ressentimentos e inconformismos. Em qualquer país é necessário que os formuladores da política estejam preparados para resistir às investidas de grupos poderosos inconformados com as decisões tomadas. É o caso, por exemplo, das empresas "derrotadas" nos processos de aquisição de armamentos, que, ao deixarem de celebrar contratos milionários, podem tentar prejudicar a continuidade do processo. Ou, ainda, pode ser o caso de ressentimentos entre alguns militares, inconformados com o controle civil sobre eles exercido. A transparência é importante ferramenta para que as decisões minimizem resistências e garantam sustentabilidade às prioridades estabelecidas.

"Representar interesses difusos e de baixa capacidade de organização" (REZENDE, 2005). Nesse aspecto, em particular, deve ser dada atenção à situação do Ministério da Defesa no Brasil. A pasta, até hoje, não logrou obter efetivo controle sobre as forças armadas nem integrá-las em um único projeto de força. Não se percebe organização capaz de reduzir os custos do sistema de defesa. O EstadoMaior de Defesa não exerce direção sobre as três forças armadas e nem mesmo exerce influência significativa sobre elas, limitando-se a ser uma assessoria fardada do ministro (LOPES, 2001; ZAVERUCHA, 2006). A falta de transparência é um grave entrave ao entendimento entre as diferentes organizações e seus pontos de vista. 
"Assegurar implementação de políticas" (REZENDE, 2005). O sistema de defesa do Brasil, nesse aspecto, apresenta importantes sucessos em paralelo com estrondosos fracassos. Mesmo com uma gestão de recursos que deixa muito a desejar, as forças armadas conseguem lograr bons resultados em áreas pontuais de grande impacto junto à sociedade. É o caso do ensino ministrado nas academias, escolas e colégios militares, reconhecido socialmente como padrão de excelência; da incorporação gradual de mulheres nas mesmas atividades desempenhadas pelos profissionais do sexo masculino; e dos serviços de busca e salvamento da Marinha e da Aeronáutica, recentemente aplaudidos, merecidamente, por seu extremo profissionalismo no caso do vôo Air France 447, perdido sobre o Atlântico. Entretanto, o controle do espaço aéreo perdeu muito de sua credibilidade com a crise do sistema ocorrida em 2007, a qual levou a questionamentos até mesmo acerca da reverenciada disciplina militar. Antes mesmo, em 2006, uma inaceitável e injustificável colisão aérea destruiu um Boeing 737 da Gol Linhas Aéreas sobre a Amazônia, exatamente onde fora feito um megainvestimento para implantação dos radares do Sistema de Vigilância da Amazônia (SIVAM). A implementação de políticas públicas na área de defesa precisa ter atenção à entrega efetiva, real, do bem público que se espera, sob pena de perda de credibilidade e, no caso de essa perda tornar-se irreversível, dar-se um verdadeiro colapso do sistema de defesa. A regra de ouro da política de defesa deve ser a de que, se se trata de uma política pública, os bens públicos esperados devem ser entregues e as contas prestadas, sem hesitações, à sociedade. Transparência deve ser palavra de ordem.

"Manter compromissos firmados com outros governos" (REZENDE, 2005). Uma das discussões mais intensas acerca das políticas de defesa, atualmente, é a da sua capacidade de gerar confiança entre os diferentes países. De fato, uma maior transparência na política de defesa, em especial no tema do orçamento de defesa, poderia contribuir decisivamente para o estabelecimento de relações de cooperação, constituindo, dessa forma, importante medida de confiança mútua. A política de defesa reflete-se diretamente na imagem que um país constrói no exterior. Por isso mesmo, deve ser eliminado o descompasso que se verifica, no Brasil, entre as políticas externa e de defesa. O resgate dessa sintonia é fundamental para que o Estado brasileiro sinalize sua intenção de manter compromissos firmados com outros países. Uma aliança de defesa com os países sul-americanos, por exemplo, deverá superar o nível do discurso e gerar resultados concretos. O Conselho de Defesa Sulamericano (CDS), iniciativa apoiada pelo Brasil, ao menos formalmente, merece ser reforçado como fórum de discussão. 
"Gerenciar conflitos e tensões políticas" (REZENDE, 2005). Nesse aspecto, os principais conflitos e tensões verificados na política de defesa do Brasil são internos ao Estado. Dizem respeito a desentendimentos e desarmonias nas relações entre as forças armadas, o Ministério da Defesa, o Itamaraty, a área orçamentária e financeira, a comunidade acadêmica e outros setores. Os militares são donos de hábitos arraigados e forte visão corporativa. As lideranças civis, por seu lado, praticamente ignoram a defesa nacional (ROCHA, 2008). A Estratégia Nacional de Defesa (BRASIL, 2008) pode haver representado um importante passo no sentido da superação desses conflitos de natureza institucional ao convocar, expressamente, os diferentes setores para juntos pensar a defesa nacional do Brasil.

A avaliação das políticas públicas pode ser orientada de acordo com, pelo menos, três vertentes: a jurídica, a política e a gerencial (VIEGAS, 2003; RODRIGUES, 2008). Não são conceitos excludentes, mas complementares. Idealmente, a avaliação das políticas públicas contemplaria as três vertentes. Uma avaliação meramente jurídica da política de defesa circunscrever-se-ia ao âmbito da lei, contentando-se com a conformação formal dos atos com a norma que a rege. A vertente política por sua vez, centra seu foco na busca da eficácia, isto é, nos resultados. Tem-se uma abordagem já mais próxima à noção de performance do que na vertente jurídica. Sob esse prisma, a política de defesa seria considerada satisfatória quando entregasse aos destinatários os bens e serviços públicos esperados: dissuasão, deterrencia, etc. É necessário, entretanto, que se tenha cuidado, pois a consideração exagerada dessa vertente poderia levar a avaliar positivamente uma política pública independentemente do custo da entrega do bem ou serviço, desconsiderando a eficiência e comprometendo a implementação de outras políticas públicas também necessárias.

A vertente gerencial da avaliação das políticas públicas, por sua vez, visa verificar se as ações desenvolvidas no âmbito de determinada política pública se orientam para os objetivos estabelecidos. O caráter da vertente gerencial (também chamada administrativa) é, sobretudo, includente. Leva em conta as noções de legalidade, de eficácia e de eficiência, tentando avaliar as políticas públicas em seu conjunto de resultados. O que a avaliação gerencial busca é aferir os resultados obtidos, mantendo-os ou aperfeiçoando-os quando satisfatórios, ou, se for o caso, reorientando-os, se percebidos desvios dos objetivos (RODRIGUES, 2008). O desafio que se coloca aos avaliadores das políticas públicas, inclusive da política de defesa, é o de consolidar este caminho, enfrentando questões relativas à forte cultura do controle meramente de conformidade (SILVA; COSTA, 2000; GARCES; SILVEIRA, 2002; MARINI, 2008). 
Em especial, deve-se buscar o aprimoramento dos instrumentos de gestão disponíveis, sobretudo dos mecanismos de contratualização de resultados. Cada vez mais fica evidente a necessidade de se estabelecer um novo paradigma de controle, baseado na ampliação de práticas de auditoria de desempenho, de forma complementar à questão da conformidade. O desenvolvimento e a consolidação de novos indicadores de desempenho e, também, uma questão a ser enfrentada (GARCIA, 2001; RODRIGUES, 2008; MARINI, 2008). E, no que se refere à política de defesa, o desafio é particularmente grande, como decorrência da singularidade do produto (output) da defesa. As já discutidas características de não-rivalidade e nãoexclusividade do bem disponibilizado estão na base dessa dificuldade de se estabelecer parâmetros claros de avaliação (GIRALDO, 2001). A rigor, a não ser quando do indesejável advento de um conflito armado, e difícil dizer se a defesa nacional "funciona" ou não.

Por fim, cabe dizer que, uma vez que as políticas públicas, naturalmente, carregam componentes ideológicos fortes e sensíveis, poucas coisas em políticas públicas acabam por ser francamente claras. Trata-se de um mundo eivado de ideologias, as quais, por definição, não são verificáveis nem mensuráveis. Daí a necessidade de que áreas técnicas, atuando com isenção de ânimo, e primando pela busca de neutralidade, liberadas de juízos pré-concebidos, atuem na avaliação de políticas públicas. Avaliações de políticas públicas devem ser feitas, de preferência, por agentes externos ao processo. Em outras palavras, na medida do possível, quem avalia deve estar fora do objeto da avaliação. No Brasil, o controle da despesa pública, o que inclui o controle dos gastos da defesa nacional, é deferido a um sistema de controle externo, o qual deve receber o apoio e o suporte de um sistema de controle interno. O controle externo compete ao Congresso Nacional, que o exerce com o apoio do TCU. O controle interno, no caso específico da defesa nacional, é realizado pela Secretaria de Controle Interno do Ministério da Defesa, pela Diretoria de Contas da Marinha (DICON), pela Diretoria de Auditoria do Exército (DAud) e pela Subsecretaria de Auditoria da Aeronáutica (SuAud).

\section{Do controle civil à redefinição estrutural: o caráter complementar das políticas de defesa de FHC e Lula.}

No que se refere à defesa nacional, o governo do Presidente Fernando Henrique Cardoso (FHC) representou um grande ponto de inflexão. Foi o primeiro momento na história de nosso país em que se procurou descaracterizar o tema da defesa como "assunto de militares" para torná-lo um tema de toda a sociedade. A principal tarefa de que se desincumbiu o governo FHC, em cujo período criou-se o 
Ministério da Defesa, foi o estabelecimento do controle civil sobre as forças armadas, exigência fundamental para a construção da ideia de uma política de defesa democrática ${ }^{5}$. Houve, também, o que foi muito importante, a ruptura definitiva com o conceito de segurança nacional, que atribuía às forças armadas o papel de "tutora" da política nacional, além da criação, no discurso, pelo menos, de uma instância de coordenação das três forças armadas singulares.

O governo do Presidente Luiz Inácio Lula da Silva (Lula) não trouxe uma ruptura, propriamente dita, com o governo FHC, no que toca à política de defesa. Assim como em outras áreas da atuação governamental, pode-se dizer que, na política de defesa, "em geral, há muito mais semelhança que diferenças" (MARINI, 2004, p. 21). Na passagem da Política de Defesa Nacional (BRASIL, 1996) de FHC para a Política de Defesa Nacional (BRASIL, 2005) de Lula, houve uma positiva manutenção da essência com leves modificações de forma. A importante complementaridade entre as políticas de defesa dos dois governos permitiu à política de defesa, nos últimos dez anos, ser tratada, pela primeira vez no Brasil, como política de Estado e não como simples plano de governo, em que pesem as críticas contrárias.

Entretanto, há que se reconhecer as importantes inovações trazidas pelo governo Lula à política de defesa do Brasil, em especial com a definição da Estratégia Nacional de Defesa (BRASIL, 2008), complemento fundamental à Política de Defesa Nacional (BRASIL, 2005). Essas inovações, em certos casos, foram profundas e de grande impacto, chegando a representar verdadeira redefinição estrutural. Entre elas destacamos as relações com a sociedade civil, as relações com a universidade e a introdução do conceito de capacidades para o planejamento de longo prazo.

No que se refere às relações com a sociedade civil, a política de defesa do governo Lula trouxe a expressa intenção de estreitamento. A ideia, muito clara na atual Estratégia Nacional de Defesa (BRASIL, 2008), é de romper com o isolamento das forças armadas e da defesa nacional como um todo, através da sociliazação do debate. Entre as mais importantes inovações, ressalta a atribuição aos órgãos da defesa nacional da responsabilidade específica de desenvolvimento de uma mentalidade de defesa na sociedade civil.

As relações entre o setor defesa nacional e a universidade também foram objeto de atenção. Desde o governo $\mathrm{FHC}$, no plano do discurso, pelo menos, já se potencializava o reconhecimento do valor das universidades como geradoras de

${ }^{5}$ E para garantir que a defesa não sirva apenas de instrumento de força a serviço de poucos beneficiários (FUCCILLE, 2006). 
conhecimento para a defesa. Esse reconhecimento tornou-se muito mais visível a partir da Estratégia Nacional de Defesa (BRASIL, 2008). A Estratégia prevê ações específicas relativas às universidades, inclusive, no que se refere à formação de quadros civis para a defesa nacional, o que é realmente inovador. As universidades deverão ser partícipes, ainda, na pesquisa e na geração de novas tecnologias. Como bem situam Domício Proença Jr. e Érico Esteves Duarte:

"A possibilidade dos tomadores de decisão terem claras as alternativas da ação governamental depende da Universidade, única capaz de coligir, sopesar e criticar fatos e alternativas, através da pesquisa, da educação, e do avanço conhecimento capazes de situar os assuntos militares como governamentais." (PROENÇA JUNIOR; DUARTE, 2007, p. 31)

Finalmente, tem-se a introdução do conceito de capacidades como norteador do planejamento de longo prazo da defesa nacional. As capacidades substituem a noção de inimigos no planejamento da defesa e podem alterar por completo o conceito de emprego das forças armadas no Brasil. Desde o governo FHC já se previa o estabelecimento de linhas de planejamento de longo prazo, contudo, foi no governo Lula, com a Estratégia Nacional de Defesa (BRAIL, 2008), que se marcou o caminho a seguir. O conceito de capacidades abre caminho para a metodologia de projeto de força, cuja ausência tem sido uma gravíssima deficiência da política de defesa.

A metodologia de projeto de força é "um sistema de conceitos que permite identificar e relacionar as variáveis necessárias à concepção de capacidades miliatres antecipadas para prover a defesa" (RAZA, 2002). No Brasil, a falta de um projeto de força faz com que o Exército seja prisioneiro do dilema resultante de concepções estratégicas opostas (dissuasão e presença) e que a Marinha, tenha adquirido um navio-aeródromo sem condições para prover o adequado apoio logístico (PROENÇA; DINIZ, 2003). Além disso, sem um projeto de força, não se logra obter uma apropriada interoperabilidade entre as forças armadas, nem mesmo entre unidades distintas de uma força singular (FLORES, 2003). Se é verdade que toda estratégia é necessariamente difícil de implementar, como resultado do fenômeno da fricção enunciado por Clausewitz (GRAY, 1999), muito mais o será sem um projeto de força capaz de minimizar os riscos.

O quadro Políticas de defesa FHC e Lula, ao final deste artigo, apresenta um resumo comparado das principais realizações dos dois governos em relação à 
defesa nacional, avaliando o caráter inovador, ou não, da política de defesa do governo Lula em relação ao governo FHC.

\section{Conclusão}

Assim como a internalização, nos meios militares e civis ligados à defesa da importância do tratamento de suas questões de forma transparente do melhor desempenho de sua implemetação são esforços fundamentais, que, no Brasil, ainda estão começando.

Ao dizer respeito à própria existência do país, a política de defesa deve ser tratada como política de Estado, acima das rivalidades partidárias e das trocas de comando no governo. As escolhas relativas à defesa nacional devem levar em conta os outros bens ou serviços públicos que deixarão de ser providos com vistas à sua implementação, sem esquecer as características específicas e o caráter essencial do "bem defesa". Essa evolução somente poderá ser obtida com o envolvimento das diferentes instâncias de gestão, pesquisa e transparência interessadas no assunto: um conjunto institucional de atores políticos, públicos e privados, muito mais amplo do que o restrito círculo das forças armadas. Oesboço de qualquer estrutura de defesa em uma democracia, para que tenha legitimidade e conte com recursos, deve vir da aprovação da sociedade.

Em um país como o Brasil, cujos problemas sociais assumem proporções tão gigantescas quanto as suas dimensões continentais, pode ser difícil justificar investimentos maiores em defesa, em detrimento de programas sociais. Por sua vez as forças armadas brasileiras queixam-se, continuamente, e com razão, dos sucessivos cortes e contingenciamentos orçamentários a que seus programas são submetidos. Contudo, não tem sido fácil garantir a aplicação de recursos públicos no setor e não se deve esperar que o país se amolde às necessidades da defesa. A política de defesa é que deve ter seus propósitos adequados às necessidades nacionais prioritárias e, para isso, a inserção da política de defesa no mais amplo debate social é um passo de primeira importância. 
Tabela 1

Políticas de defesa FHC e Lula.

\begin{tabular}{|c|c|c|c|}
\hline \multirow{2}{*}{ Campo } & \multirow{2}{*}{ Governo FHC } & \multicolumn{2}{|r|}{ Governo Lula } \\
\hline & & Inovação & Conteúdo inovador \\
\hline $\begin{array}{c}\text { Relações } \\
\text { interinstitucionais }\end{array}$ & $\begin{array}{l}\text { Afirmação da ideia da } \\
\text { subordinação das forças } \\
\text { armadas ao poder civil. }\end{array}$ & Nenhuma & \\
\hline Doutrina & $\begin{array}{l}\text { Desvinculação da ideia de } \\
\text { segurança nacional e } \\
\text { orientação da defesa nacional } \\
\text { para resposta a agressões } \\
\text { externas. }\end{array}$ & Nenhuma & \\
\hline $\begin{array}{l}\text { Integração e } \\
\text { Coordenaçãa }\end{array}$ & $\begin{array}{l}\text { Tentativa de fazer do Ministério } \\
\text { da Defesa uma instância de } \\
\text { integração e coordenação dos } \\
\text { esforços das três forças } \\
\text { armadas. }\end{array}$ & Nenhuma & \\
\hline Objetivos & $\begin{array}{l}\text { Tentativa de estabelecer } \\
\text { objetivos claros para a defesa } \\
\text { nacional. }\end{array}$ & Alguma & $\begin{array}{l}\text { O uso das forças armadas na } \\
\text { garantia da lei e da ordem não foi } \\
\text { abolido, mas, foi retirado do âmbito } \\
\text { da política de defesa. }\end{array}$ \\
\hline Instrumentos & $\begin{array}{l}\text { Ênfase na diplomacia e na } \\
\text { dissuasão. }\end{array}$ & Alguma & $\begin{array}{l}\text { Embora a ênfase na diplomacia haja } \\
\text { sido reafirmada, o componente } \\
\text { militar da defesa foi mais valorizado } \\
\text { e tratado de forma mais específica. }\end{array}$ \\
\hline $\begin{array}{l}\text { Relações } \\
\text { exteriores }\end{array}$ & $\begin{array}{l}\text { Reconhecimento das forças } \\
\text { armadas como instrumento de } \\
\text { projeção internacional. }\end{array}$ & Alguma & $\begin{array}{l}\text { Foi expressamente prevista a } \\
\text { participação das forças armadas } \\
\text { brasileiras nos arranjos coletivos de } \\
\text { defesa, sob patrocínio do Conselho } \\
\text { de Segurança da ONU, o que era } \\
\text { apenas subentendido. }\end{array}$ \\
\hline $\begin{array}{l}\text { Relações com a } \\
\text { sociedade civil }\end{array}$ & $\begin{array}{l}\text { Expressa intenção de estreitar } \\
\text { as relações entre as forças } \\
\text { armadas e a sociedade civil. }\end{array}$ & Muita & $\begin{array}{l}\text { A Estratégia Nacional de Defesa } \\
\text { atribui aos órgãos da defesa nacional } \\
\text { da responsabilidade específica de } \\
\text { desenvolvimento de uma } \\
\text { mentalidade de defesa na sociedade } \\
\text { civil. }\end{array}$ \\
\hline $\begin{array}{l}\text { Relações com a } \\
\text { universidade }\end{array}$ & $\begin{array}{l}\text { Reconhecimento do valor das } \\
\text { universidades. }\end{array}$ & Muita & $\begin{array}{l}\text { A Estratégia Nacional de Defesa prevê } \\
\text { ações específicas relativas às } \\
\text { universidades, inclusive, a formação } \\
\text { de quadros civis para a defesa } \\
\text { nacional. }\end{array}$ \\
\hline $\begin{array}{l}\text { Indústria de } \\
\text { defesa }\end{array}$ & $\begin{array}{l}\text { Reconhecimento da } \\
\text { importância do setor industrial } \\
\text { para a defesa nacional. }\end{array}$ & Muita & $\begin{array}{l}\text { A indústria de defesa foi objeto de } \\
\text { tratamento muito mais detalhado, } \\
\text { em especial após a Estratégia } \\
\text { Nacional de Defesa. Além disso, foi } \\
\text { prevista a integração da indústria de } \\
\text { defesa com outros países, o que é } \\
\text { inédito. }\end{array}$ \\
\hline
\end{tabular}




\begin{tabular}{|c|c|c|c|}
\hline Ameaças & $\begin{array}{l}\text { Definidas em seus aspectos } \\
\text { gerais e excluindo as supostas } \\
\text { ameças internas, que } \\
\text { vigoraram durante o regime } \\
\text { militar. }\end{array}$ & Muita & $\begin{array}{l}\text { Foi expressamente prevista a } \\
\text { ameaça cibernética como uma } \\
\text { preocupação para a defesa nacional, } \\
\text { algo totalmente inovador. }\end{array}$ \\
\hline $\begin{array}{c}\text { Estrutura } \\
\text { organizacional }\end{array}$ & $\begin{array}{l}\text { Tentativa de integração das } \\
\text { forças singulares, inicialmente } \\
\text { com a própria criação do } \\
\text { Ministério. }\end{array}$ & Muita & $\begin{array}{l}\text { O Estado-maior conjunto das forças } \\
\text { armadas será a primeira tentativa de } \\
\text { unificação do componente militar- } \\
\text { operacional da defesa, superando a } \\
\text { simples direção política do ministro. }\end{array}$ \\
\hline $\begin{array}{l}\text { Localização } \\
\text { estratégica das } \\
\text { unidades } \\
\text { militares } \\
\end{array}$ & $\begin{array}{l}\text { Priorização da Amazônia e do } \\
\text { Atlântico Sul como teatros de } \\
\text { operação das forças armadas. }\end{array}$ & Muita & $\begin{array}{l}\text { A Estratégia Nacional de Defesa } \\
\text { trouxe orientações claras para a } \\
\text { localização das unidades militares. }\end{array}$ \\
\hline $\begin{array}{c}\text { Prioridades de } \\
\text { defesa }\end{array}$ & $\begin{array}{l}\text { Tentativa de estabelecer } \\
\text { prioridades claras para a } \\
\text { defesa nacional. }\end{array}$ & Muita & $\begin{array}{l}\text { A Estratégia Nacional de Defesa } \\
\text { superou o caráter inicial da definição } \\
\text { de prioridades e estabeleceu uma } \\
\text { verdadeira hierarquização de } \\
\text { concepções estratégicas. }\end{array}$ \\
\hline Planejamento & $\begin{array}{l}\text { Tentativa de estabelecer linhas } \\
\text { de longo prazo para o } \\
\text { planejamento da defesa. }\end{array}$ & Muita & $\begin{array}{l}\text { A introdução do conceito de } \\
\text { capacidades como norteador do } \\
\text { planejamento de longo prazo, em } \\
\text { substituição à noção de inimigos } \\
\text { abre caminho para a metodologia de } \\
\text { Projeto de Força e pode alterar por } \\
\text { completo todo o conceito de } \\
\text { emprego das forças armadas. }\end{array}$ \\
\hline
\end{tabular}

\section{Referências Bibliográficas}

AGUILAR, S. L. C. Políticas de defesa e orçamentos militares no Cone Sul. In: D'ARAÚJO, Maria Celina; SOARES, Samuel Alves; MATHIAS, Suzeley Kalil. (Org.). Defesa, Segurança Internacional e Forças Armadas: textos selecionados do Primeiro Encontro da Associação Brasileira de Estudos de Defesa. 1 ed. Campinas: Mercado de Letras, 2008, p. 101-121.

ALSINA JÚNIOR, J. P. S. A síntese imperfeita: articulação entre política externa e política de defesa na Era Cardoso (1995-2002). Dissertação de mestrado. Brasília: Universidade de Brasília (UnB), 2002.

BID (Banco Interamericano de Desenvolvimento). A política das políticas públicas: progresso social e econômico na América Latina. Relatório 2006 do BID e do David 
Rockfeller Center for Latin American Studies, Harvard University. Rio de Janeiro: Elsevier; Washington, DC: BID, 2007.

BRASIL. Ministério da Defesa. Estratégia Nacional de Defesa. Disponível em: <https://www.defesa.gov.br/eventos_temporarios/2009/estrategia/arquivos/estrat egia_defesa_nacional_portugues.pdf> Acesso em: [24 fev. 2010].

BRASIL. Política de Defesa Nacional. [Online] Aprovada pelo Decreto 5484, de 30.06.2005. Brasília: 2005. Disponível em:

<https://www.defesa.gov.br/pdn/index.php?page=home>. Acesso em: [15 fev. 2010].

BRASIL. Política de Defesa Nacional. [Online] Governo Fernando Henrique Cardoso. Coleção Documentos da Presidência da República. Brasília: Presidência da República. 1996. Disponível em:<http://www.planalto.gov.br/publi_04/colecao/DEFES.htm>. Acesso em: [15 fev. 2010].

BRANDÃO, M. P. Ciência, tecnologia, inovação e a defesa nacional. Parcerias estratégicas, [Online], Brasília, Centro de Gestão e Estudos Estratégicos (CGEE), n. 20, p. 831-860, ISSN 1413-9375, 2005. Disponível em:

<http://www.cgee.org.br/arquivos/p_20_2.pdf>. Acesso em: [18 jul. 2009].

BRIGAGÃO, C. Caixa-preta na defesa. O Globo, Rio de Janeiro, 03 set. 2007.

CANO, G. T. Os desafios do desenvolvimento humano da ONU, a partir do relatório do desenvolvimento humano 1990. Dissertação de mestrado. São Paulo: Pontifícia Universidade Católica (PUC), 2006.

CASTELAN, D. R. Segurança e defesa na década de 90: interpretações do Itamaraty e Forças Armadas. In: I SIMPÓSIO EM RELAÇÕES INTERNACIONAIS DO PROGRAMA DE PÓS-GRADUAÇÃO EM RELAÇÕES INTERNACIONAIS SAN TIAGO DANTAS (UNESP, UNICAMP, e PUC-SP) Nov 12-14, 2007. Disponível em: <http://www.santiagodantassp.locaweb.com.br/br/simp/artigos/castelan.pdf >. Acesso em: [18 jul. 2009].

CEPIK, M. A. C. Serviços de inteligência: agilidade e transparência como dilemas de institucionalização. Tese de doutorado. Rio de Janeiro: Instituto Universitário de Pesquisa do Rio de Janeiro (IUPERJ), 2001.

FERNANDES, F. B. As relações civil-militares durante o governo Fernando Henrique Cardoso-1995/2002. Dissertação de mestrado. Brasília: Universidade de Brasília (UnB), 2006. 
FLORES, M. C. Uma estratégia para o Brasil. In: CICLO DE DEBATES SOBRE A ATUALIZAÇÃO DO PENSAMENTO BRASILEIRO EM MATÉRIA DE DEFESA E SEGURANÇA. Brasília, Ministério da Defesa, 2003.

FREY, K. Políticas públicas: um debate conceitual e reflexões referentes à prática da análise de políticas públicas no Brasil. Planejamento e políticas públicas, Rio de Janeiro, Instituto de Pesquisa Econômica Aplicada (IPEA), n. 21, p. 211.259, ISSN 0103.138, jun 2000.

FUCCILLE, L. A. Democracia e questão militar: a criação do Ministério da Defesa no Brasil. Tese de doutorado. Campinas: Universidade Estadual de Campinas (Unicamp), 2006.

GARCES, A; SILVEIRA, J. P. Gestão pública orientada para resultados no Brasil. Revista do serviço público (RSP), Brasília, Escola Nacional de Administração Pública (ENAP), nº 4, ISSN 0034-9240, p. 53-77, out-dez, 2002.

GARCIA, R. C. A reorganização do processo de planejamento do governo federal: o PPA 2000-2003. Texto para discussão, Brasília, Instituto de Pesquisa Econômica Aplicada (IPEA), n 726, ISSN 1415-4765, maio, 2000.

GARCIA, R. C. Subsídios pra organizar avaliações da ação governamental. Texto para discussão, Brasília, Instituto de Pesquisa Econômica Aplicada (IPEA), nº 776, ISSN 1415-4765, janeiro, 2001.

GIRALDO, J. K. Defense Budgets and Civilian Oversight. [Online] Monterrey, CA, The Center for Civil-Military Relations Naval Postgraduate School, 2001. Disponível em <https://www.ccmr.org/public/library_file_proxy.cfm/lid/1864/f/defense_budgets. doc>. Acesso em [18 jul. 2009].

GRAY, C. S. Why strategy is difficult. Joint Force Quarterly (JFQ), Washington, DC, National Defense University (NDU), ISSN 1070-0692, Summer, 1999.

KINGDON, J. Agendas, Alternatives and Public Policies. 3 ed. New York: Harper Collins, 2003.

LASCOUMES, P; LEGALES, P. Introduction: understanding public policy through its instruments - from the nature of instruments to the sociology of public policy instrumentation. Governance: An International Journal of Policy, Administration and Institutions, Malden, Blackwell Publishing, v. 20, n. 1, ISSN 0952-1895, Jan. 2007. 
LOPES, R. Oportunidades para civis na condução da defesa nacional: o caso do Brasil. In: RESEARCH AND EDUCATION IN DEFENSE AND SECURITY STUDIES (REDES). Washington, DC, May 22-25, 2001. Disponível em <http://www.ndu.edu/chds/REDES2001/Papers/Block2/CivilianMilitary\%20Relations\%20Panel-Generational\%20Change/Lopes.CivilMilitary\%20panel.rtf>. Acesso em: [15 jul. 2009].

MANKIW, G. Principles of Economics. 4th Ed. Fort Worth, USA: The Dryden Press, 2006.

MARINI, C. Gestão pública no Brasil: temas preservados e emergentes na formação da agenda. In: VII CONGRESSO DA ASSOCIAÇÃO DE ESTUDOS BRASILEIROS, Brazilian Studies Association (BRASA), jun. 2004.

Um decálogo da boa gestão pública: os desafios de um Estado para resultados. In: XIII CONGRESSO INTERNACIONAL DEL CLAD SOBRE LA REFORMA DEL ESTADO Y DE LA ADMINISTRACIÓN PÚBLICA, Buenos Aires, Centro Latinoamericano de Administración para el Desarrollo (CLAD), 4.7, nov 2008.

MARQUES, A. A. A Atividade de inteligência vista como política pública do Estado. Revista de Sociologia e Política, Curitiba, Universidade Federal do Paraná (UFPR), n. 22, p. 213-215, ISSN 0104-4478, jun. 2004. Resenha de: CEPIK, Marco. Espionagem e democracia: agilidade e transparência como dilemas na institucionalização de serviços de inteligência. Rio de Janeiro: Fundação Getúlio Vargas (FGV), 2003a.

Concepções de defesa nacional: 1950-1996. Dissertação de mestrado. Campinas: Universidade Estadual de Campinas (Unicamp), 2001.

Concepções estratégicas brasileiras no contexto internacional do pós-guerra fria. Revista de Sociologia e Política, Curitiba, Universidade Federal do Paraná (UFPR), n. 20, p. 69.85, ISSN 0104-4478, jun. 2003b.

OLIVEIRA, E. R. Considerações políticas sobre a defesa nacional. [Online] Com ciência: revista eletrônica de jornalismo científico, São Paulo, Sociedade Brasileira para o Progresso da Ciência (SBPC), ISSN 1519-7654. Disponível em:

<http://www.comciencia. br/comciencia/handler. php? section $=8 \&$ edicao $=12 \& i d=10$ 1>. Acesso em: [18 jul. 2009].

PROENÇA JUNIOR, D; DUARTE, É. E. Os estudos estratégicos como base reflexiva da defesa nacional. Revista Brasileira de Política Internacional, Brasília, Instituto Brasileiro de Relações Internacionais, v. 50, n. 1, p. 29-46, ISSN 0034-7329, 2007. 
PROENÇA Jr., D. e DINIZ, E. A falta que faz um projeto para as Forças Armadas. O Estado de São Paulo, São Paulo, 03 jan. 2003.

RAZA, S. G. Projeto de força: o elo ausente em reformas de defesa. In: RESEARCH AND EDUCATION IN DEFENSE AND SECURITY STUDIES (REDES). Brasília, 2002.

REZENDE, Flávio da Cunha. Instituições e políticas públicas no Brasil. In: I SEMINÁRIO DE CIÊNCIA POLÍTICA DA UFPE DEMOCRACIA E INSTITUIÇÕES, 2005. Recife: Universidade Federal de Pernambuco (UFPE), Nov. 2005.

ROCHA, A. J. R. Prioridades claras, necessidades ocultas e o plano estratégico nacional de defesa. [Online] Revista Liberdade e Cidadania, Brasília, Fundação Liberdade e Cidadania, Ano 1, n. 2, ISSN 1983-9162, out/dez 2008. Disponível em: <http://www.flc.org.br/revista/arquivos/121543798793361.pdf >. Acesso em: [18 jul. 2009].

RODRIGUES, E. S. O Plano Plurianual 2008-2011 e o Programa de Aceleração do Crescimento. In: XIII CONGRESSO INTERNACIONAL DEL CLAD SOBRE LA REFORMA DEL ESTADO Y DE LA ADMINISTRACIÓN PÚBLICA, Buenos Aires, Centro Latinoamericano de Administración para el Desarrollo (CLAD), 4-7, nov. 2008.

RUA, M. G. Análise de políticas públicas: conceitos básicos. In: RUA, M. G; CARVALHO, M. I. V. (org.). O estudo da política: tópicos selecionados. Brasília: Paralelo 15, 1998. Coleção Relações Internacionais e Política. Disponível em: <http://vsites.unb.br/ceam/webceam/nucleos/omni/observa/downloads/pol_publi cas.PDF>. Acesso em: [24 fev. 2010].

SANDLER, T; HARTLEY, K. The economics of defense. Cambridge surveys of economic literature. ISBN 0.521.44728.3 (pbk.). New York: Cambridge University Press, 1995.

SANTANA, V. J. Leitura crítica do discurso da política de defesa nacional. Dissertação de Mestrado. Brasília: Universidade de Brasília (UnB), 2007.

SANTISO, C. Legislatures and budget oversight in Latin America: strenghtening public finance accountability in emerging countries. [Online] OECD Journal on Budgeting, Paris, Organisation for Economic Co-operation and Development (OECD), v. 4, n. 2, p. 47.76, ISSN 1608-7143, jun. 2003. Disponível em: <bepress.com/cgi/viewcontent.cgi?article=1042\&context=eloi>. Acesso em: $[18$ jul. 2009]. 
SILVA, M. I. C. Amazônia e política de defesa no Brasil (1985-2002). Dissertação de Mestrado. Marília: Universidade Estadual Paulista Júlio de Mesquita Filho (UNESP), 2004.

SILVA, P. L. B.; COSTA, N. R. Avaliação de políticas públicas na América do Sul: a avaliação de programas públicos - uma estratégia de análise. In: V CONGRESSO INTERNACIONAL DEL CLAD SOBRE LA REFORMA DEL ESTADO Y DE LA ADMINISTRACIÓN PÚBLICA, Santo Domingo, Centro Latinoamericano de Administración para el Desarrollo (CLAD), 24-27, Oct. 2000.

SOUZA, C. "Estado do campo" da pesquisa em políticas públicas no Brasil. Revista Brasileira de Ciências Sociais, São Paulo, Associação Nacional de Pós-graduação e Pesquisa em Ciências Sociais (Anpocs), v. 18, n. 51, p. 15.20, ISSN 0102.6909, fev. 2003.

"Políticas públicas: uma revisão da literatura." Sociologias, Porto Alegre, ano 8, n. 16, p. 20-45, ISSN 1517.4522, jul./dez. 2006.

TORGERSON, D. "Contextual orientation in policy analysis: the contribution of Harold D. Lasswell." Policy Sciences, Amsterdam, Elsevier Science Publishers, n. 18, ISSN 0032-2687, p. 241-261, 1985.

VIEGAS, W. Avaliação de políticas públicas: experiências brasileiras - procedimentos metodológicos. In: VIII CONGRESSO INTERNACIONAL DEL CLAD SOBRE LA REFORMA DEL ESTADO Y DE LA ADMINISTRACIÓN PÚBLICA. Panamá, Centro Latinoamericano de Administración para el Desarrollo (CLAD), 28-31, Oct. 2003.

WEBER, M. A política como vocação. Tradução de Maurício Tragtenberg. Brasília: Editora Universidade de Brasília, 2003.

ZAVERUCHA, J. "A fragilidade do Ministério da Defesa brasileiro." Revista de Sociologia e Política, Curitiba, Universidade Federal do Paraná (UFPR), n. 25, p. 165. 175, ISSN 0104-4478, jun. 2006.

Carlos Wellington de Almeida · carlosla@tcu.gov.br

Recebido para publicação em outubro de 2009. Aprovado para publicação em fevereiro de 2010. 